\title{
Occult pancreatic cancer with recurrent acute pancreatitis
}

\author{
C. Wilson and C.W. Imrie \\ Division of Surgery, Royal Infirmary, Glasgow G4 OSF, UK.
}

\begin{abstract}
Summary: A patient with occult pancreatic carcinoma associated with recurrent acute pancreatitis is reported. Endoscopic retrograde cholangiopancreatography after the first attack was normal, the diagnosis being made at repeat examination 10 months later.
\end{abstract}

\section{Introduction}

Recurrent bouts of acute pancreatitis in which no aetiological factor can be implicated, is an infrequent but troublesome clinical problem. Alcohol and gallstones should be carefully excluded and endoscopic retrograde cholangiopancreatography (ERCP) may be of value in delineating other causes (Cotton \& Beales, 1974). We report a case in which ERCP after the first attack of acute pancreatitis demonstrated no abnormality, the underlying cause manifesting 10 months later.

\section{Case report}

A 66 year old man was admitted in April 1983 with severe abdominal pain and vomiting. Serum amylase was grossly elevated ( $5090 \mathrm{IU} / 1$, normal range $70-300$ IU/1) consistent with a diagnosis of acute pancreatitis. He had a past medical history of tuberculosis, chronic airways disease and hypertension and had recently been treated for a chest infection.

Oral cholecystogram and ultrasound excluded a gallstone aetiology, there was no history of alcohol abuse and none of the rarer aetiological causes of pancreatitis could be implicated. ERCP (Figure 1) showed a normal pancreatic duct and biliary tree with no evidence of gallstones.

He had a further attack of acute pancreatitis 2 months later when ultrasound was again normal. There were 3 further attacks of pancreatitis over the next 5 months, on each occasion his abdominal pain and serum amylase resolving completely within a few days of admission. He remained otherwise well between attacks.

Eight months after his original admission he developed more persistent abdominal pain and barium meal confirmed a duodenal ulcer. Therapy with

Correspondence: C. Wilson, F.R.C.S.

Accepted: 10 February 1986 ranitidine was commenced and because of anaemia ferrous sulphate was added. He was readmitted with further abdominal pain and vomiting in February 1984. Alkaline phosphatase was elevated $(600 \mathrm{U} / 1$, normal range $80-280 \mathrm{U} / 1$ ) and ultrasound showed enlargement of the head and body of the pancreas but

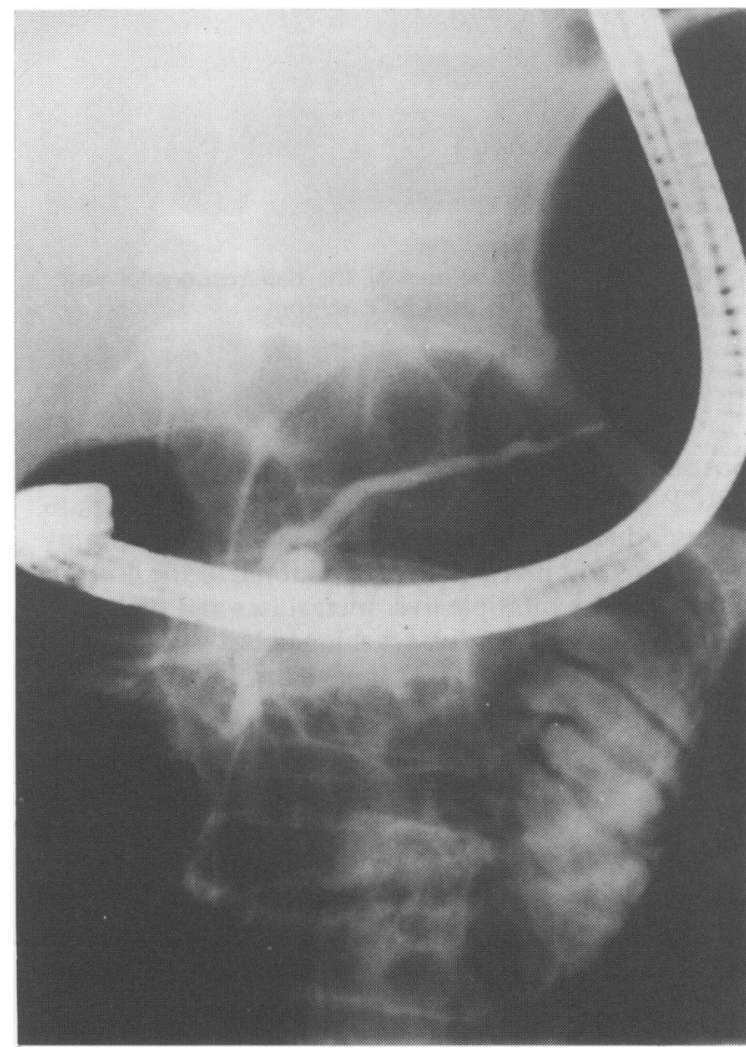

Figure 1 Shows normal pancreatic duct,

(C) The Fellowship of Postgraduate Medicine, 1986 


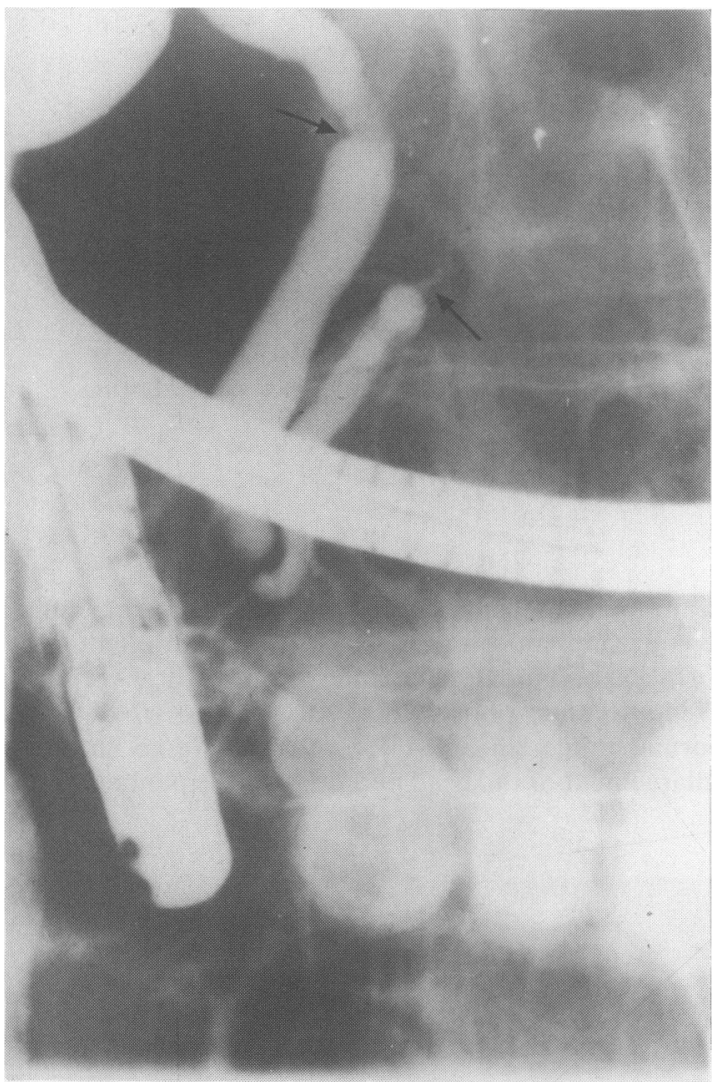

Figure 2 Shows strictures of the pancreatic duct and common bile duct caused by carcinoma.

no other liver or biliary tract abnormality. Repeat ERCP (Figure 2) showed strictures of the main pancreatic duct and common bile duct. Laparotomy identified definitively a large carcinoma of the body of pancreas with multiple liver metastases and ascites. A cholecystjejunostomy was fashioned but he continued to deteriorate and died 22 days later.

\section{References}

ALLAN, B.J., TOURNUT, R. \& WHITE, T.T. (1973). Intraductal activation of pancreatic zymogen behind a carcinoma of the pancreas. Gastroenterology, 65, 412.

COTTON, P.B. \& BEALES, J.S.M. (1974). Endoscopic pancreatography in management of relapsing acute pancreatitis. British Medical Journal, 1, 608.

\section{Discussion}

Alcohol abuse and gallstones account for over $80 \%$ of cases of acute pancreatitis in our practice (Imrie et al., 1978) and further attacks are usually prevented by attention to these factors. Despite full and thorough screening no aetiological factor can be implicated in a proportion of cases. ERCP provides high quality biliary radiology and overlooked gallstones may be discovered. It may also demonstrate unsuspected pancreatic duct abnormalities some of which may be amenable to surgical treatment (Cotton \& Beales, 1974). Furthermore, in a recent study, no patient shown to have a normal pancreatic duct had further recurrence of acute pancreatitis (Hamilton et al., 1982). Clearly, with continuing bouts of acute pancreatitis, consideration should be given to repeating the ERCP, even if previously normal.

Pancreatic carcinoma is a recognized but infrequent cause of acute pancreatitis. In a collective review of 12 series of acute and recurrent acute pancreatitis, 26 of 1912 patients $(1.4 \%)$ were found to have underlying pancreatic carcinoma (Durr, 1979). The present case is particularly unusual for the frequency of attacks of acute pancreatitis and it also highlights the delay that may occur in diagnosing the carcinoma when pancreatitis and carcinoma co-exist, a point previously noted by Gambill (1971). Given the poor prognosis associated with pancreatic carcinoma, it seems unlikely that earlier diagnosis would have altered the outcome in this patient.

Mild focal pancreatitis is commonly seen in association with pancreatic carcinoma. Significant pancreatitis by histological criteria, as distinct from the above, was found in $10.2 \%$ of 255 patients with pancreatic or ampullary carcinoma; interestingly, in only $3 \%$ of these patients was there a history suggestive of acute pancreatitis (Gambill, 1971).

The exact mechanism of pancreatitis in pancreatic carcinoma, as in other forms of pancreatitis, is as yet unexplained. Ductal obstruction with intraductal zymogen activation has been postulated as a cause (Allan et al., 1973) and there is some evidence that tumour cells themselves may produce enzymes capable of activating trypsinogen (Ossowski et al., 1973).

DURR, G.H. (1979). Acute pancreatitis. In The Exocrine Pancreas, Howat, H.T. \& Sarles, H. (eds). p. 360. W.B. Saunders: London.

GAMBILL, E.E. (1971). Pancreatitis associated with pancreatic carcinoma: a study of 26 cases. Mayo Clinic Proceedings, 46, 174. 
HAMILTON, I., BRADLEY, P., LINTOTT, D.J., MCMAHON, M.J. \& AXON, A.T.R. (1982). Endoscopic retrograde cholangiopancreatography in the investigation and management of patients after acute pancreatitis. British Journal of Surgery, 69, 504.

IMRIE, C.W., BENJAMIN, I.S., FERGUSON, J.C., McKAY, A.J., MACKENZIE, I., O'NEILL, J. \& BLUMGART, L.H. (1978). A single centre double-blind trial of Trasylol therapy in primary acute pancreatitis. British Journal of Surgery, 65, 337.

OSSOWSKI, L., QUIGLEY, J.P., KELLERMAN, G.M. \& REICH, E. (1973). Fibrinolysis associated with oncogenic transformation. Requirement of plasminogen for correlated changes in cellular morphology, colony formation in agar and cell migration. Journal of Experimental Medicine, 138, 1056. 